\title{
Mental models, pictures, and text: Integration of spatial and verbal information
}

\author{
Introductory remarks
}

As I listened to a symposium on "Mental models, pictures, and text: Integration of spatial and verbal information," given on May 2, 1991, during the meetings of the Midwestern Psychological Association in Chicago, I thought that the research would interest Memory \& Cognition's readers. The central focus is on the processes involved in the integration of spatial and verbal information gleaned from pictures and text, topics that are critically important to our understanding of human cognition. Accordingly, I invited the participants to submit their manuscripts to the journal, with the understanding that they would undergo the standard editing process. The following set is the result. I hope that you find it as challenging as I did.

Margaret Jean Intons-Peterson

Editor 